\title{
Early experience affects adult personality in the red junglefowl: a role for cognitive stimulation?
}

Josefina Zidar, Enrico Sorato, Ann-Marie Malmqvist, Emelie Jansson, Charlotte Rosher, Per Jensen, Anna Favati and Hanne Løvlie

\section{Journal Article}

\section{Tweet}

N.B.: When citing this work, cite the original article.

Original Publication:

Josefina Zidar, Enrico Sorato, Ann-Marie Malmqvist, Emelie Jansson, Charlotte Rosher, Per Jensen, Anna Favati and Hanne Løvlie, Early experience affects adult personality in the red junglefowl: a role for cognitive stimulation?, Behavioural Processes, 2017, 134, 78-86.

http://dx.doi.org/10.1016/j.beproc.2016.06.003

Copyright: Elsevier

http://www.elsevier.com/

Postprint available at: Linköping University Electronic Press

http://urn.kb.se/resolve?urn=urn:nbn:se:liu:diva-131304

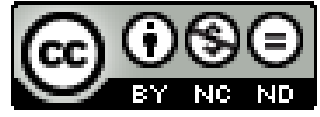


Early experience affects adult personality in the red junglefowl: a role for cognitive stimulation?

Josefina Zidar ${ }^{a \#}$, Enrico Sorato ${ }^{\mathrm{a \#}}$, Ann-Marie Malmqvist ${ }^{\mathrm{a}}$, Emelie Jansson ${ }^{\mathrm{a}}$, Charlotte Rosher ${ }^{\mathrm{a}, \mathrm{b}}$, Per Jensen ${ }^{a}$, Anna Favatic ${ }^{c}$ Hanne Løvlie ${ }^{a *}$

${ }^{a}$ IFM Biology, Linköping University, 58183 Linköping, Sweden.

${ }^{\mathrm{b}}$ Faculty of Life Sciences, University of Manchester, M13 9LP Manchester, UK.

${ }^{c}$ Department of Zoology, Stockholm University, 10691 Stockholm, Sweden.

Email addresses:

JZ: josefina.zidar@liu.se

ES: enrico.sorato@liu.se

A-MM: annma378@student.liu.se

EJ: emelie.jansson@liu.se

CR: charlotte@rosher.net

PJ: per.jensen@liu.se

AF: anna.favati@zoologi.su.se

HL: hanne.lovlie@liu.se

\# Equal contribution

* Corresponding author: hanne.lovlie@liu.se 


\begin{abstract}
Despite intense research efforts, biologists are still puzzled by the existence of animal personality. While recent studies support a link between cognition and personality, the directionality of this relationship still needs to be clarified. Early-life experiences can affect adult behaviour, and among these, cognitive stimulation has been suggested theoretically to influence personality. Yet, the influence of early cognitive stimulation has rarely been explored in empirical investigations of animal behaviour and personality. We investigated the effect of early cognitive stimulation on adult personality in the red junglefowl (Gallus gallus). To this end, we assessed adult behaviour across a number of personality assays and compared behaviour of individuals previously exposed to a series of learning tasks as chicks, with that of control individuals lacking this experience. We found that individuals exposed to early stimulation as adults were more vigilant and performed fewer escape attempts in personality assays. Other behaviours describing personality traits in the fowl were not affected. We conclude that our results support the hypothesis that early stimulation can affect aspects of adult behaviour and personality, suggesting a hitherto underappreciated causality link between cognition and personality. Future research should aim to confirm these findings and resolve their underlying dynamics and proximate mechanisms.
\end{abstract}

Keywords: Developmental plasticity; Boldness; Exploration; Gallus gallus; Juvenile learning; Neophobia; Vigilance 


\section{Introduction}

The last two decades have witnessed a rapid increase in research interest surrounding consistent individual differences in behaviour, also known as animal personality (Gosling et al., 2001; Dall et al., 2004; Sih et al., 2004; Réale et al., 2007). Personality has been described in a broad range of species (Gosling, 2001; Carere and Maestripieri, 2013) and demonstrated to have important ecological and evolutionary consequences (Dall et al., 2004; Sih et al., 2004; Smith and Blumstein, 2008; Carere and Maestripieri, 2013). Despite this, the factors shaping variation in animal personality are still poorly understood. While genetic mechanisms have been demonstrated in a number of species, their contribution to personality variation is generally limited (e.g. van Oers et al., 2005; van Oers and Sinn, 2011; Dochtermann et al., 2015). This leaves ample scope for environmental effects to contribute to personality (Stamps and Groothuis, 2010; Groothuis and Trillmich, 2011). Early life experiences in particular are predicted to have far-reaching consequences for the development of individual personality traits (Stamps and Groothuis, 2010), yet such effects have rarely been empirically explored (but see e.g. Naguib et al., 2011; Schuett et al., 2013; Krause and Naguib, 2014; van Oers et al., 2015). Further studies of the developmental processes affecting personality are therefore needed to improve our understanding of both the proximate mechanisms underlying personality variation and its evolutionary consequences (Stamps and Groothuis, 2010; Groothuis and Trillmich, 2011).

There are several studies demonstrating that early experiences can influence adult behaviour, suggesting that personality traits may also be affected. However, most of the evidence is limited to laboratory studies of mammals. Deprivation of maternal care has been shown to increase anxiety-like behaviour in rodents and primates (Papaioannou et al., 2002; Barr et al., 2003; Neto et al., 2012), while early handling can have the opposite effect and reduce anxiety (reviewed in Chapillon et al., 2002). Similarly, early environmental enrichment can have profound effects on behaviour (e.g. review by van Praag et al., 2000; Christensen et al., 2004; Lazic et al., 2007; Patzke et al. 2009), for example by reducing stress reactivity (Chapillon et al., 2002) and by enhancing explorative behaviour later in life (e.g. Joseph, 1979; Christensen et al., 2004). These effects likely occur due to changes in the developing neuronal and physiological systems. For example, early experiences can modify the development of central neuronal systems involved in regulation of stress and emotion (Levine et al., 1957; Meaney et al., 1991; van Praag et al., 2000). Early experiences can thus have critical effects on brain development, physiology and behaviour, and may also have long-lasting consequences affecting personality.

Despite this, exploration of the implications of early experience on the development of animal personality is still largely limited to theoretical models (e.g. Wolf et al., 2008; Bergmüller and Taborsky, 2010; Dingemanse and Wolf, 2010; Duckworth, 2010). Among the growing number of empirical studies 
conducted to date, there is increasing evidence for effects of early experience on adult personality. For example, in guppies (Poecilia reticulata), unpredictable feeding regimes increased boldness and exploration later in life (Chapman et al., 2010). In birds, reduced dietary micronutrients reduced adult boldness (male zebra finches, Taeniopygia guttata, Noguera et al., 2015), while the personality of foster parents (zebra finches, Schuett et al., 2013), and the condition of parents (zebra finches, Krause and Naguib, 2014) influenced exploration in offspring as adults. These behavioural changes may arise through effects on the developing central neural system. For example, in marsh tits (Parus palustris, Clayton and Krebs, 1994), and in domestic chicks (Gallus gallus domesticus, Freire and Cheng, 2004), early stimulation generates changes in the hippocampus and activation of monoaminergic pathways.

Among the early life experiences potentially affecting adult personality, cognitive stimulation has been suggested to have important effects (Carere and Locurto, 2011). Complex interplays between personality and cognition have been recently suggested, mainly based on theoretical grounds (Carere and Locurto, 2011; Sih and Del Giudice, 2012; Griffin et al., 2015), but also by some empirical studies (e.g. Guilette et al. 2009, 2011; 2015; Exnerová et al., 2010; Light et al., 2011; Amy et al., 2012; Titulaer et al., 2012). Nevertheless, the directionality of any causal link between personality and cognition is still largely unresolved (Carere and Locurto, 2011; Sih and Del Giudice, 2012; Griffin et al., 2015). Theoretically, any relationship can be due to one of three scenarios; (i) personality and cognition may share a common underlying mechanism, (ii) personality may affect cognition, or (iii) cognition may affect personality (Matzel et al., 2003; Light et al., 2008). Examples of shared underlying factors include variation in speed-accuracy trade-offs (Sih and Del Giudice, 2012), or shared underlying control structures (Coppens et al., 2010). The latter has been suggested by artificial selection experiments showing that selection for personality traits can affect performance in cognitive tasks (Groothuis and Carere, 2005), most likely by influencing the shared HPA-axis control of behaviours (reviewed in Groothuis and Carere, 2005; Mathot et al., 2012). On the other hand, individual differences in personality traits like exploration and boldness could affect individual cognitive abilities if for example explorative individuals interact more with their environment and therefore acquire more information (Light et al., 2008). However, as far as we know, this scenario has not been experimentally supported. On the contrary, while mice exposed to novel environments showed increased exploration tendency, there was no effect on learning (Matzel et al., 2008). Finally, variation in individual cognitive abilities and experiences may affect personality. For example, individuals that can process information faster may as a consequence explore faster, while slow individuals would be constrained in doing so (Light et al., 2011; Carere and Locuto, 2011). In experiments on mice, individuals with higher performance across several learning tests habituated faster to a novel environment and were more explorative, 
which was interpreted as support for cognition affecting behaviour and not vice versa (Light et al., 2011).

In fact, few studies have explicitly tested the hypothesis that cognition can affect personality (but see Light et al., 2011), and we are not aware of any specifically testing whether early cognitive stimulation may have long-lasting effects on personality traits. We therefore explored this possibility in the red junglefowl (Gallus gallus), a species for which we have developed behavioural assays that capture variation in personality (Favati et al., 2014a, b, Favati et al., 2015), where personality stabilises after ontogeny (Favati et al., 2015), and can be affected by the social environment (Favati et al., 2014b). Here, we investigated how early stimulation aimed to stimulate cognition affects adult personality by exposing young chicks to a series of tasks involving learning, an important cognitive process (Shettleworth, 2010). We hypothesise that cognitive stimulation will most likely affect behaviour linked to information processing, such as vigilance and/or exploration of novel environments. On the other hand, we predicted that if early stress, rather than cognitive stimulation, is affecting adult behaviour, fear-related behaviour (such as latency to move after induction of tonic immobility, Forkman et al., 2007), will be affected the most.

\section{Methods}

\subsection{Animals and housing}

We used a total of 175 red junglefowl $\left(n_{\text {males }}=95, n_{\text {females }}=80\right.$ ) from a captive, pedigree-bred population kept at Linköping University, Sweden, and hatched in two years (2013: $n_{\text {males }}=42, n_{\text {females }}=$ $\left.45, \mathrm{n}_{\text {families }}=18 ; 2015: \mathrm{n}_{\text {males }}=53, \mathrm{n}_{\text {females }}=35, \mathrm{n}_{\text {families }}=28\right)$. To facilitate individual recognition, all individuals were marked with wing-tags directly after hatching. Birds that hatched the same year were all kept in the same group. Up to 5 weeks of age, chicks were held indoor in mixed-sex groups (range 15-30 individuals per group). The size of the enclosures increased with age $\left(0.5 \mathrm{~m}^{2}-3 \mathrm{~m}^{2}\right)$. At 6 weeks of age, birds were moved to a chicken facility $10 \mathrm{~km}$ north of Linköping (to a facility called 'WoodGush'). Males and females were separated and held in two $3 \mathrm{~m}^{2}$ indoor enclosures, with an additional outdoor enclosure $\left(3 \mathrm{~m}^{2}\right)$ attached. Commercial poultry feed, water, dust bath and perches were available ad libitum, apart from when participating in experiments. Tests were conducted according to ethical requirements in Sweden (Linköping Ethical committee, ethical permit numbers 122-10 and 5013).

\subsection{Experimental set up}


To investigate the effect of cognitive stimulation on personality later in life, individuals were divided into two treatment groups: one group consisted of individuals exposed to experiences aimed to cause early cognitive stimulation ('stimulated test individuals', $\mathrm{n}_{\text {total }}=86 ; 2013: \mathrm{n}_{\text {males }}=25, \mathrm{n}_{\text {females }}=27 ; 2015$ : $\mathrm{n}_{\text {males }}=17 ; \mathrm{n}_{\text {females }}=17$ ), the other group consisted of control individuals ('control individuals', $\mathrm{n}_{\text {total }}=$ 89; 2013: $\mathrm{n}_{\text {males }}=17, \mathrm{n}_{\text {females }}=18 ; 2015: \mathrm{n}_{\text {males }}=36, \mathrm{n}_{\text {females }}=18$ ). We anticipated that exposure to multiple and prolonged cognitive experiences were needed to have the potential to influence adult personality. Therefore, early stimulation consisted of a battery of learning tasks carried out between day 3 post-hatching and 5 weeks of age, and targeting a range of cognitive abilities. The tests were partially different between the two years (see below), but served the same purpose of stimulating cognition. Control individuals were not exposed to cognitive tests, but were otherwise handled and fed in a similar way as the test individuals. This included that control individuals were caught and handled, and were allowed to move around in the test arena, to eat mealworms, and to interact with the test stimuli. This procedure was aimed at minimizing any difference in treatment other than cognitive stimulation, in other words to minimize differential exposure to handling, novelty and stress between the two groups of birds. Following sexual maturity ( $\geq 5$ months, Zuk \& Johnsson, 1998) adult behaviour was assayed across a battery of personality tests (see below).

\subsubsection{Early cognitive stimulation}

Cognitive stimulation consisted of the following cognitive tasks: associative-, and reversal learning (2013, 2015); generalization and spatial learning (2013); and selective attention (2015) (see supplementary information, table S1). The range of tests used is a consequence of concomitant research on different learning abilities in the fowl. However, because these tests were quite labourintensive, we were not able to perform all tasks in both years for practical reasons. Both years nevertheless included a range of learning tasks of different complexity.

For all learning tasks, chicks were trained and tested singly. With the exception of the spatial learning task, all cognitive tasks were conducted in identical arenas, made of mesh boxes $(28 \times 18 \times 37 \mathrm{~cm}$, length $\times$ width $\times$ height) covered with cardboard on all sides. Each training session lasted for 15 minutes, unless the chick was no longer motivated by the reward. If the task was not learnt within a given session, training resumed in following session, after $\geq 1$ hour of rest.

\subsubsection{Associative learning task}

Associative learning is a simple learning task where a reward is associated with a stimulus (Dickinson et al., 1985). At day 1 post-hatching, chicks were familiarised with temporary isolation and the test arena. At day 3 post-hatching, chicks were trained to associate a colour cue with a food reward 
presented in one of two coloured bowls $(5 \times 3 \mathrm{~cm}, \varnothing \times$ height $)$ with matching coloured signs $(9 \times 9 \mathrm{~cm})$ behind the bowls. The food reward was placed near the front edge of the bowl to make sure that the chicks could not see the reward from a distance. In 2013, birds were trained on either the colour blue or green as the rewarded stimulus. In 2015 , all birds where trained on black as rewarded stimulus, while white was always unrewarded. After a chick had chosen between the rewarded and unrewarded stimulus and had eaten the reward (if choosing the rewarded stimulus), it was collected and tested again. Each chick was allowed unlimited number of such trials within the $15 \mathrm{~min}$ time limit of a training session, unless it reached the learning criterion (see below). If learning was not achieved, the chick was exposed to another session. A task was considered learnt based on the number of correct (i.e. the rewarded) consecutive choices: 5 times in a row for 2013 and 6 times in a row for 2015. We chose to increase the learning criteria in 2015 compared to 2013 to make the criteria more conservative. One chick in 2013 and two chicks in 2015 did not learn the associative learning task. The 2013 chick did however learn the spatial learning task (see below) and was kept in the analyses. The two chicks in 2015 were not trained further and were excluded from analyses.

\subsubsection{Reversal learning task}

A reversal learning task was performed after the associative learning task (i.e. at 5-7 days of age). In this task, the colour cue that was unrewarded in the associative learning task was now rewarded, while the previously rewarded colour cue was now unrewarded. Reversal learning is a more complex learning task as it includes extinction of a previously learned association between reward and stimulus, and learning of a new association (Coppens et al., 2010; Titulaer et al., 2012). Training and testing were otherwise conducted as described above for associative learning. A total of 9 birds did not learn the reversal learning task (2013: 3, 2015: 6), but were not excluded from the remaining battery of cognitive tests.

In 2013, chicks were allowed a maximum of 10 training sessions over 4 days to complete associative and reversal learning, while in 2015, chicks were allowed a maximum of 6 training sessions per test over 5 days of testing, to complete the association and reversal tasks. These differences were due to logistical reasons (i.e. availability of researchers that could train the birds).

\subsubsection{Generalization task}

In 2013, a random sub-sample of 67 chicks in the stimulated treatment, 13-15 days old, was exposed to a generalization task following Osorio et al., 1999. Chicks were trained to associate red and yellow with food rewards placed in triangular shaped paper cones $(3 \times 1 \mathrm{~cm})$, during 7 separate 6 min sessions over 3 days. During training, both the rewarded (red and yellow) cones were presented, together with 
grey unrewarded cones ( 2 cones of each colour, see Osorio et al. 1999 for more details). In the testing phase, chicks were exposed to a previously unexperienced colour (orange, 3 cones), which was an intermediate colour to the two previously rewarded red and yellow, and presented together with 3 red or yellow cones, and 3 grey cones (Osario et al., 1999). All cones were unrewarded in the test (Osario et al., 1999). We scored the first 10 choices the chicks made and continued scoring the chicks' choices continuously until the chicks had chosen both the orange and the red or yellow cone eight times.

\subsubsection{Selective attention test}

In 2015, a random sub-sample of chicks exposed to early stimulation, consisting of 50 chicks 21-25 days old, was exposed to a complex learning task set up to investigate variation in selective attention (similar to Kolata et al., 2007). In short, chicks first learned to associate one of two colour cues with a reward (white was rewarded, while black was unrewarded as described under reversal learning), before learning to associate a symbol (an outline of an orange circle on a grey background) with a reward, (while an outlined cross symbol was left unrewarded), before being tested in the hierarchical attention paid to colour over cue (see below). Each association was considered learned if the chick did 6 correct choices in a row. To ensure that chicks had established the association between symbol and reward, they were re-exposed on the following day to the same setup, and had to make 9 out of 10 correct choices before being tested in the actual selective attention test. During the test, chicks were presented with the same orange symbols as during training, but now presented on the previously rewarded white background (i.e. the colour rewarded in the reversal learning task). Chicks were allowed a maximum of 10 training sessions over the 6 days that the training lasted, to complete the training for the selective attention task. Eight individuals did not reach the first learning criteria and an additional ten chicks did not reach the second learning criteria. Thus 32 birds were tested in the selective attention test.

\subsubsection{Spatial learning task}

In 2013, all chicks in the stimulated treatment were exposed to a simple spatial learning task at five weeks of age. Each chick was trained to learn to locate a reward (a piece of a mealworm in a bowl) in a U-shaped arena $(76 \times 114 \mathrm{~cm})$. Chicks were initially helped to locate the reward by a trail of worms. As training continued chicks soon started to search for the reward without help. When a chick reached the reward and had eaten it, it was gently picked up and tested again. When the chick moved directly to the reward without stopping or turning around five times in a row, it was considered to have learned the task. Chicks were allowed as much time and number of trials as they needed to locate the reward 
and learn the task, which all chicks did within 80 trials, but from six individuals that were not able to learn the task due to lack of motivation to eat mealworms.

\subsubsection{Assessing adult personality}

As adults (5 months old), all individuals (test individuals and controls) were tested in a novel arena -, novel object- and a tonic immobility test. Whether a bird was a test bird or a control was unknown to the tester and all birds were thus handled the same way. All individuals were assayed alone.

\subsubsection{Novel arena test}

To quantify variation in exploration/activity and neophobia/boldness, we used a novel arena test designed and validated on this and another population of fowl (Favati et al. 2014a, b, 2015). The novel arena $(2 \times 2 \mathrm{~m})$ was subdivided into four equal-sized imaginary squares, had peat as substrate and empty, familiar food and water containers were placed in the arena to block the bird's full view of the arena and thus encourage exploration. The test started by placing the bird in one corner of the arena. The following behaviours were quantified: 'latency to move' (i.e. latency in seconds until the bird started moving after being introduced into the arena), 'activity' (i.e. locomotion; proportion of time walking and to a minor extent running), 'exploration' (i.e. number of new squares visited, 0-3, defined as the number of imaginary squares visited other than the one which the bird was initially placed and thus started in), 'foraging' (i.e. proportion of time spent with its head down close to the ground either pecking or searching for food), 'vigilance' (i.e. proportion of time spent standing or walking with eyes open and the head high above shoulder-height), and 'number of escapes' (i.e. number of times a bird tried to escape from the arena). Choice of behaviours was based on previous studies describing personality traits in the fowl (Favati et al., 2014a, b, 2015). Behaviour was quantified by direct observations in 2013, while in 2015 it was recorded by two video cameras set up at two different angles to cover the whole arena. Behaviours were scored by instantaneous sampling every $10 \mathrm{sec}$ for the 10 min the test lasted.

\subsubsection{Novel object test}

To score variation in object-related neophobia (Greggor et al., 2015) we performed a novel object test directly following the novel arena test (similar to Favati et al., 2014a, b, 2015). A novel object (a spherical plush toy measuring $15 \mathrm{~cm}$ and with ca $2 \mathrm{~cm}$ large yellow and black eyes) was placed in the arena directly following the novel arena test. The object was introduced as far away from the focal bird as possible. The same behaviours described for the novel arena test were recorded over the same duration of time (10 $\mathrm{min})$. 


\subsubsection{Tonic immobility test}

Tonic immobility is a commonly used test of fear response in birds (Forkman et al., 2007) and has been previously employed in studies of fowl behaviour, including our study population (Favati et al., 2015). To induce tonic immobility, birds were placed on their back in a V-shaped wooden stand $(20 \times 10 \mathrm{~cm})$, with a light pressure applied by the experimenter to the breast while also loosely holding a hand over the birds' head for $15 \mathrm{sec}$. Thereafter the pressure was released and the latency to first head movement was recorded (sensu Favati et al., 2015). A maximum latency of 10 min was given and the test was aborted if 10 minutes had elapsed. If the bird jumped up on its feet within $3 \mathrm{sec}$ following the removal of the pressure by the hand, the procedure was repeated up to a total of 4 times (and recorded as 'number of inductions'). If the bird was still not induced into tonic immobility after 4 attempts, it received a score of $0 \mathrm{sec}$. The observer ensured that direct eye contact with the test animal was avoided.

\subsection{Statistical analyses}

Statistical analyses were conducted using the R software (version 3.1.2; R Development Core Team 2015).

Associations between behavioural variables were assessed by calculating Spearman correlation coefficients, with significance calculated via bootstrapping (1000 iterations).

Factors affecting latencies to move (sec) in the novel arena- and novel object tests were analysed with mixed effects Cox proportional hazard models, implemented in the R package 'Coxme' (Therneau, 2012) and suitable for the analysis of right-censored latencies (Fox, 2015).

To investigate factors affecting variation in activity, foraging and vigilance (proportions of $10 \mathrm{sec}$ sampling intervals in which the behaviour occurred), these behaviour were analysed using generalized linear mixed models (GLMMs) conducted with the R statistical package 'glmmADMB' (Skaug et al., 2011). Full models including all random effects, predictors of interest and their interactions (see below), were first considered and used to select the most appropriate family distribution (binomial vsbetabinomial to model over-dispersion), link function (logit vs. cloglog), and whether or not to include zero-inflation in the model based on comparisons of model AIC scores (Zuur et al., 2009). For each behavioural variable analysed, models with lowest AIC values were retained as the best full model, and used to select the random effect structure, again based on AIC scores (see below). 
To investigate factors affecting exploration, number of squares visited (0-3) was modelled using GLMMs with a Poisson family distribution and a log link function.

Because escape behaviour occurred relatively rarely (in only $31.8 \%$ of arena tests), number of escape attempts $(0-10)$ was analysed using hurdle models, which treat zero outcomes and non-zero counts as two separate categories: the occurrence of the behaviour (binary: yes/no) was first modelled using a binomial family distribution, and the number of escapes ( $>0$ only) was subsequently analysed by conducting zero-truncated Poisson and negative binomial models.

To further assess fear-related behaviour, number of trials $(1-4)$ needed to induce tonic immobility was also modelled using zero-truncated Poisson and negative binomial family distributions, while the latency to move after induction of tonic immobility was analysed with mixed effect Cox proportional hazard models, as done for latencies in the novel arena and novel object tests. The best distribution families and link functions were again selected based on model AIC scores (Zuur et al., 2009).

To account for potential non-independence of behavioural responses from repeatedly tested individuals (i.e. across novel arena -, and novel object tests) and from the same families, full models including individual identity nested within family identity as random intercept terms were compared with their simpler nested models, having the same full fixed effect specification, but featuring either individual identity, family identity or no random term (Zuur et al., 2009). Upon selection of the random effect structure, best fixed effects structures were selected by comparing AIC scores of models with different combinations of predictors, and their two-way interactions. For behaviours in the novel arena and novel object tests, predictors included early stimulation (stimulated vs. controls), sex (male vs. female), year (2013 vs. 2015), and test type (novel arena vs. novel object). For variables from the tonic immobility test, predictors were early stimulation, sex, and year. In addition, when analysing latency in tonic immobility, number of trials needed to induce the state, was also included in the models, to account for a possible effect of previous induction attempts on TI response.

To facilitate comparisons of effect sizes within and between models, and model interpretation, all model predictors were centred by subtraction of their mean values (see Schielzeth, 2010). AIC scores of each model were compared with the best model score (lowest AIC value): models with $\triangle \mathrm{AIC}$ values $(\triangle A I C=$ focal model $A I C$ - best model $A I C)<4$ were retained as probable, and featured in the reduced final candidate model sets (Anderson and Burnham, 2002). More complex models with higher AIC scores compared to simpler nested models, were removed from the final sets. To obtain average effect sizes and associated standard errors (R package 'MuMIn', Barton, 2013), model averaging was 
conducted on the resulting final model sets, by the use of full average method (Grueber et al., 2011). Final models are presented in table 2.

\section{Results}

\subsection{Intra-and inter-relatedness among behavioural variables}

Within-behaviour correlations indicated weak to moderate individual behavioural consistency (personality) between the novel arena and novel object test, highest for vigilance and foraging behaviour (table 1).

Most behavioural variables were weakly to moderately correlated between each other (table 1), with the exception of foraging and vigilance which were strongly negatively related. The correlation structure did not differ in any obvious manner between the two test types.

\subsection{Factors affecting expression of behaviour}

Parameter estimates are provided as mean \pm standard error predicted by final models.

Latency to move was shorter in the novel object test compared to the novel arena test (novel arena: 55.9 \pm 9.3 ; novel object: $33.7 \pm 7.3$; table $2 \mathrm{a}$ ), and females exhibited on average longer latencies compared to males (males: $34.1 \pm 9.1$, females: $62.2 \pm 15.5$; table 2 a). Individuals took less time to start

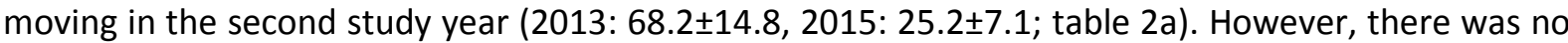
effect of previous exposure to cognitive testing.

Activity was higher in the novel object test compared to the novel arena test (novel arena: $0.09 \pm 0.01$, novel object: $0.13 \pm 0.01$; table $2 b$ ), and females were less active than males (males: $0.14 \pm 0.01$, females: mean $=0.09 \pm 0.01$; table $2 b$ ). There was no difference in activity between the two study years, nor with respect to previous exposure to cognitive testing.

On the other hand, exploration was marginally lower during the novel object test (novel arena: $1.9 \pm 0.1$, novel object: mean $=1.7 \pm 0.1$; table $2 \mathrm{c}$ ), and higher in the second study year (2013: $1.5 \pm 0.1,2015$ : $2.1 \pm 0.1$; table $2 \mathrm{c}$ ), while females were $25 \%$ less explorative than males (males: $2.0 \pm 0.1$, females: $1.5 \pm 0.1$; table 2c). Like activity, exploration was not affected by early stimulation.

Vigilance increased for individuals exposed to early stimulation (stimulated: $0.38 \pm 0.02$, controls: $0.45 \pm 0.02$ ), with these individuals being $25 \%$ more vigilant than control individuals (table $2 \mathrm{~d}$, figure 
1a). Vigilance did not differ between the novel arena- and novel object tests, but females were less vigilant than males (males: $0.48 \pm 0.02$, females: $0.34 \pm 0.02$; table $2 \mathrm{~d}$ ), and birds were less vigilant in the

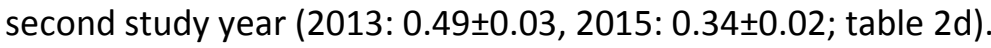

Stimulated individuals foraged marginally less than controls (stimulated: $0.32 \pm 0.02$, controls: $0.38 \pm 0.02$ ), and foraging decreased in the novel object test (novel arena: $0.39 \pm 0.02$, novel object: $0.30 \pm 0.02$; table 2 e). Females foraged on average $27 \%$ more than males (males: $0.31 \pm 0.02$, females: $0.39 \pm 0.03$; table $2 \mathrm{e})$. There was no effect of year on foraging.

The probability of observing escapes in a given test $(0 / 1)$ was not predicted by either year, sex, test type or stimulation. However, within tests in which escapes occurred, the number of escape attempts was $30 \%$ lower for stimulated individuals, compared to controls (stimulated: $2.5 \pm 0.2$, controls: $1.8 \pm 0.3$; figure $1 \mathrm{~b}$, table $2 \mathrm{f})$. Escape attempts did not differ according to test type, year or sex.

Finally, it took more attempts to induce tonic immobility in females, compared to males, although this sex difference was weak and only marginally supported (males: $1.7 \pm 0.1$, females: $1.9 \pm 0.1$; table $2 \mathrm{f}$ ); none of the other predictors affected number of inductions. Latency to terminate tonic immobility was not explained by any of the considered predictors.

\section{Discussion}

We have here shown that in red junglefowl, exposure to stimulation early in life in the form of several learning tasks, can influence adult behaviour and personality. The observed effects were behaviourspecific: early stimulation increased adult vigilance, and decreased the frequency of individual escape attempts in the novel arena- and novel object-tests. Other behaviours were not affected by the early stimulation individuals were exposed to. Moreover, while sex-differences in behavioural traits, including personality, are often observed in the fowl (e.g. Favati et al., 2015), in this study we did not observe sex-specific effects of early stimulation on the measured behaviour. This suggests that there are general underlying causal pathways behind the stimulation effect, as opposed to sex-specific ones.

In principle, there are several potential mechanisms through which early stimulation can cause alterations of behaviour. Effects of handling and early stress have been shown to affect anxiety-like behaviour (Chapillon et al., 2002; Papaioannou et al., 2002; Barr et al., 2003; Neto et al., 2012), while early enrichment may enhance explorative behaviour later in life (e.g. van Praag et al., 2000; Christensen et al., 2004; Lazic et al., 2007; Patzke et al., 2009). Latency to move and activity in novel arena and novel object tests are routinely used to quantify individual fearfulness in domestic animals, 
including chickens (Forkman et al., 2007). If differential exposure to stress was underlying the early stimulation effect on adult behaviour we observed in this study, we would have expected fear related behaviour to be the most affected by the early stimulation our test individuals were exposed to. Contrary to this prediction, neither latencies to move nor activity differed between control and stimulated birds. In fact, we find it unlikely that test and control birds were differentially exposed to stress since both groups were calmly handled and habituated to the test set ups without apparent signs of distress. On the other hand, we found that in stimulated birds vigilance increased, while number of escapes decreased. In the fowl, vigilance is highly consistent over time and context (as demonstrated both here and in previous studies, Favati et al., 2014a, b, 2015), and therefore describes variation in personality in the species. Escape behaviour was considerably less consistent within individuals, and the extent to which it may be considered a proxy for a personality trait (e.g. sociability, see below), is not clear. Nonetheless, both behaviours appeared to be affected by early stimulation to a similar extent. While a positive correlation between vigilance and escape behaviour may suggest fearfulness as a common underlying causal factor, the observation that the effect of early stimulation on these two behaviours was in opposite directions further reduces increased fearfulness or enhanced susceptibility to stressful conditions as possible mechanisms behind the stimulation effect. Nevertheless, we cannot entirely exclude that the effect of early stimulation on adult behaviour was caused by some other mechanism, such as the experience of performing a task and independently from cognitive stimulation. Further experimental work, designed to investigate the exact mechanism involved, is needed to disentangle these alternatives. Moreover, more empirical and theoretical work is needed to improve our understanding of the relationships between type of early stimulation and adult behaviour, in particular with respect to the dynamics and consequences of bidirectional feedbacks between personality and cognition (Sih et al., 2004; Sih and Del Giudice, 2012).

In theory, several neuronal pathways and structures may have been affected by early cognitive stimulation and have led to long lasting effects on adult fowl personality. At a cellular and molecular level, reorganization of brain structure (Krech et al., 1960; Rosenzweig, 1962; Moser et al., 1994) can alter brain monoaminergic systems (Bock and Braun, 1998) and gene expression (Groothuis and Trillmich, 2011). Mechanistically, behavioural modifications caused by early cognitive stimulation can occur due to positive or negative feedback loops (Sih et al., 2004; Sih and Del Giudice, 2012). For example, cognitive stimulation may place individuals in a positive affective state, making them more prone to explore their environment for gathering new information, and leading to further stimulation. In the red junglefowl, higher vigilance in stimulated individuals may reflect an increase in alertness and general attentiveness to the surrounding environment. Novel stimuli improve sustained attention compared to more repetitive tasks (e.g. humans, Oken et al., 2006), and moreover cognitive function 
and alertness are linked in the pre-frontal cortex (humans, Thomas et al., 2000). The multitude of early cognitive stimulation that the test birds were exposed to may have engaged the attentional system of their brain in a persistent manner, resulting in the observed difference between the two groups of birds. While it is commonly assumed that increased attentiveness is a response to perceived predation risk (Lima and Dill, 1990), vigilant individuals may also be gathering other types of information. Previous work in the domestic fowl has demonstrated that increased vigilance may be a response to higher perceived predation risk (Evans et al., 1993; Zidar and Løvlie, 2012; Favati et al., 2014a), yet there is also evidence relating vigilance to social dominance in males (Favati et al., 2014a, b), consistent with a function in risk assessment of the social context (e.g. intra-sexual competition). Vigilance may therefore be adaptive not only in terms of anti-predator strategy, but may have also a function in social information gathering. Similarly, escape behaviour is not only a response to fear, but has in chickens been suggested to be driven by social reinstatement (Forkman et al., 2007). The observed reduction in escape behaviour by stimulated birds is thus intriguing in this respect. Further investigation is needed to ascertain if cognitive stimulation and environmental enrichment may also have long lasting effects on individual sociability.

Finally, we found that other behaviours known to describe personality in the junglefowl, and that are related to fear and activity/exploration (Favati et al., 2014a, b; 2015), were unaffected by the early stimulation our test birds were exposed to. This lack of effect could be due to one or more of the following: (i) the behaviour in question is not affected by the stimulation individuals were exposed to, or the effect is not permanent; (ii) the developmental window when stimulation is important was missed; or (iii) the type of stimulation used was not of the right type or intensity. These possibilities will be discussed below.

First, we exposed birds to a series of learning tasks and only included individuals in the analyses that passed our learning criteria for at least one of the tasks they were exposed to. Thus, all stimulated individuals were exposed to at least two cognitive tests where they successfully solved at least one of them. This should limit the likelihood of insufficient stimulation and suggests that the unaffected personality traits may be insensitive to the administered stimulation. An alternative possibility is that the exposure to early stimulation may have affected all behaviours, but that some were further altered later in life, thereby obscuring the previous effect of stimulation. This can occur if a behaviour that is based on information gained during early experiences is adjusted during later periods, such as following independence or at first reproduction, when the old information may be updated according to current environmental and social conditions (Groothuis and Trillmich, 2011). In this way, accumulated feedback can modify previous effects of early experiences. This process has been 
suggested for early reward sensitivity (Groothuis and Trillmich, 2011). The birds we used were all exposed to the same environment between exposure to learning tasks and adulthood, which could potentially explain why experimental and control birds behaved similarly in many aspects. Moreover, in the fowl important physiological and social changes are known to occur during development and affect personality (Favati et al., 2015).

Secondly, consequences of early exposure can depend on when the exposure occurs in life (reviewed in Neto et al., 2012). Although in principle it is possible that the developmental window required for stimulation to be effective was missed in our study, the fact that we observed an effect on some behaviours suggest that this is a less likely explanation for why other behaviours remained unaffected. Then again, if behaviours are not controlled by the same brain regions, behaviour-specific sensitive windows may occur.

Thirdly, a perhaps more probable explanation for why some behaviours remained unaffected by exposure to early learning tasks, is that the type of stimulation was not of the correct type, or was not enough to trigger an effect. Importantly, in our study only one learning task (and conducted in the first year only) was a spatial task. Exposure to spatial stimulation from rearing in complex environments increased exploration in quail chicks (Colinus virginianus, Lazic et al., 2007), and a similar effect was found in ostriches (Struthio camelus, Christensen and Nielsen, 2004). Increased exposure to tasks encouraging movement and spatial awareness may therefore have been needed to stimulate adult activity and exploration, while the more visually stimulating tasks we mainly used may have been most effective on vigilance and escape behaviour.

\section{Conclusions}

Taken together, we have here shown that early stimulation in the form of exposure to a series of learning tasks between the age of 3 days and 5 weeks, affected adult vigilance, a personality trait in the red junglefowl, and escape behaviour. We therefore show a possible causal relationship where cognitive stimulation affects personality later in life. Yet, not all personality traits were affected by this early stimulation, possibly due to the specific types of cognitive tests used, which may have been effective for some behaviours but not others. Further research is encouraged to investigate the dynamics of personality-specific alterations, and their underlying mechanisms.

\section{Acknowledgement}

We are grateful to Lejla Bektic and Petros Batakis for game keeping, Alexandra Balogh, Caroline Sollevi and Louise Hedlund for help with behavioural observations. Funding was awarded by the Royal 
Swedish Academy of Sciences (to JZ), the Swedish Research Council (to PJ), ERC (Advanced Research Grant "Genewell" to PJ), from the LiU programme "Future research leaders", the Swedish Research Council Formas (to $\mathrm{HL}$ ) and Carl Trygger's Foundation (to $\mathrm{HL}$ ). The project was carried out within the framework of the Centre of Excellence for Animal Welfare Science.

\section{References}

Amy, M., van Oers, K., Naguib, M. 2012. Worms under cover: relationships between performance in learning tasks and personality in great tits (Parus major). Anim Cogn. 5, 763-770. (doi: $10.1007 / \mathrm{s} 10071-021-0500-3)$

Anderson, D.R., Burnham, K.P., 2002. Avoiding pitfalls when using information-theoretic methods. J. Wildl. Manag. 66, 912-918.

Barr, C.S., Newman, T.K., Becker, M.L., Parker, C.C., Champoux, M., Lesch, K.P., Higley, J.D., 2003. The utility of the non-human primate model for studying gene by environment interactions in behavioral research. Genes Brain Behav. 2, 336-340.

Barton, K., 2013. MuMIn: multi-model inference. R package version 1.

Bergmüller, R., Taborsky, M., 2010. Animal personality due to social niche specialisation. Trends Ecol. Evol. 25, 504-511.

Bock, J., Braun, K., 1998. Differential emotional experience leads to pruning of dendritic spines in the forebrain of domestic chicks. Neural Plasticity 6, 17-27.

Carere, C., Locurto, C., 2011. Interaction between animal personality and animal cognition. Curr. Zool. 57, 491-498.

Carere, C., Maestripieri D., (Eds.) 2013. Animal personalities: Behavior, physiology, and evolution. Chicago (IL): University of Chicago Press.

Carter, A.J., Feeney, W.E., Marshall, H.H., Cowlishaw, G., Heinsohn, R., 2013. Animal personality: what are behavioural ecologists measuring? Biol. Rev. 88, 465-475.

Chapillon, P., Patin, V., Roy, V., Vincent, A., Caston, J., 2002. Effects of pre- and postnatal stimulation on developmental, emotional, and cognitive aspects in rodents: a review. Dev. Psychobiol. 41, 373-387.

Chapman, B.B., Morell, L.J., Krause, J. 2010. Unpredictability in food supply during early life influences boldness in a fish. Behav. Ecol. 21, 501-506. (doi:10.1093/beheco/arq003)

Christensen, J.W., Nielsen, B.L., 2004. Environmental enrichment for ostrich, Struthio camelus, chicks. Anim. Welf. 13, 119-124.

Clayton, N.S., Krebs, J.R., 1994. Hippocampal growth and attrition in birds affected by experience. Proc. Natl. Acad. Sci. 91, 7381-7384. 
Coppens, C.M., De Boer, S.F., Koolhaas, J.M., 2010. Coping styles and behavioural flexibility: towards underlying mechanisms. Proc. R. Soc. B. 365, 4021-4028. (doi:10.1098/rstb.2010.0217)

Dall, S.R.X., Houston, A.I., McNamara, J.M., 2004. The behavioural ecology of personality: consistent individual differences from an adaptive perspective. Ecol. Lett. 7, 734-739.

Dall, S.R.X., Griffith, S.C., 2014. An empiricist guide to animal personality variation in ecology and evolution. Front. Ecol. Evol. 2. (doi: 10.3389/fevo.2014.00003)

Dickinson, A., 1985. Actions and habits: the development of behavioural autonomy. Phil. Trans. R. Soc. B. $308,67-78$.

Dingemanse, N.J., Wolf, M., 2010. Recent models for adaptive personality differences: a review. Phil. Trans. R. Soc. B. 365, 3947-3958.

Dochtermann, N.A., Schwab, T., Sih, A., 2015. The contribution of additive genetic variation to personality variation: heritability of personality. Proc. R. Soc. B. 282, 20142201. (doi: 10.1098/ rspb.2014.2201)

Duckworth, R. A., 2010. Evolution of personality: developmental constraints on behavioral flexibility. The Auk 127, 752-758.

Evans, C.S., Evans, L., Marler, P., 1993. On the meaning of alarm calls-functional reference in an avian vocal system. Anim. Behav. 46, 23-38.

Exnerová, A., Svádová, K. H., Fucíková, E., Drent, P., Stys, P. 2010. Personality matters: individual variation in reactions of naive bird predators to aposematic prey. Proc. R. Soc. B. $277,723-728$. (doi:10.1098/rspb.2009.1673)

Favati, A., Leimar, O., Løvlie, H., 2014a. Personality predicts social dominance in male domestic fowl. PLoS One. 9, e103535.

Favati, A., Leimar, O., Radesäter, T., Løvlie, H., 2014b. Social status and personality: stability in social state can promote consistency of behavioural responses. Proc. R. Soc. B. 281, 20132531.

Favati, A., Zidar, J., Thorpe, H., Løvlie, H., 2015. The ontogeny of personality traits in red junglefowl, Gallus gallus. Behav. Ecol. (doi:10.1093/beheco/arv177)

Forkman, B., Boissy, A., Meunier-Salaun, M.C., Canali, E., Jones, R.B., 2007. A critical review of fear tests used on cattle, pigs, sheep, poultry and horses. Physiol. Behav. 92, 340-374.

Fox, G.A. 2015. What you don't know can hurt you censored and truncated data in ecological research. In: Fox, G.A Negrete-Yankelevich, S., Sosa, V. J. (Eds.) Ecological statistics: Contemporary theory and application. Oxford University Press, USA.

Freire, R., Cheng, H.W., 2004. Experience-dependent changes in the hippocampus of domestic chicks: a model for spatial memory. Europ. J. Neurosci. 20, 1065-1068.

Gosling, S.D., 2001. From mice to men: what can we learn about personality from animal research? Psychol. Bull. 127, 45-86. 
Greggor, A.L., Thornton, A., Clayton, N.S., 2015. Neophobia is not only avoidance: improving neophobia tests by combining cognition and ecology. Curr. Opinion Behav. Sci. 6, 82-89.

Griffin, A.S., Guillette, L.M., Healy, S.D., 2015. Cognition and personality: an analysis of an emerging field. Trends Ecol. Evol. 30, 207-214.

Groothuis, T. G., Carere, C., 2005. Avian personalities: characterization and epigenesis. Neurosci. Biobehav. Rev. 29, 137-150.

Groothuis, T.G.G., Trillmich, F., 2011. Unfolding personalities: the importance of studying ontogeny. Dev. Psychobiol. 53, 641-655. (doi: 10.1002/dev.20574)

Grueber, C. E., Nakagawa, S., Laws, R. J., Jamieson, I. G., 2011. Multimodel inference in ecology and evolution: challenges and solutions. J. Evol. Biol. 24, 699-711.

Guillette, L.M., Reddon, A.R., Hurd, P.L., Sturdy, C.B., 2009. Exploration of a novel space is associated with individual differences in learning speed in black-chapped chickadees, Poecile atricapillus. Behav. Proc. 82, 265-270. (doi: 10.1016/j.beproc.2009.07.005)

Guillette, L.M., Reddon, A.R., Hoeshele, M., Sturdy, C.B., 2011. Sometimes slower is better: slowexploring birds are more sensitive to changes in a vocal discrimination task. Proc. R. Soc. B. 278, 767-773. (doi 10.1098/rspb.2010.1669)

Guillette, L.M., Hahn, A.H., Hoeschele, M., Przyslupski, A.M., Sturdy, C.B., 2015. Individual differences in learning speed, performance accuracy and exploration behaviour in black-chapped chickadees. Anim. Cogn. 18, 165-178. (doi:10.1007/s10071-014-0787-3)

Joseph, R., 1979. Effects of rearing and sex on maze learning and competitive exploration in rats. J. Psychol. 101, 37-43.

Kolata. S., Light, K., Grossman, C.G., Hale, G., Matzel, L.D., 2007. Selective attention is a primary determinant of the relationship between working memory ad general learning ability in outbred mice. Lern. Mem. 14, 22-28. (doi:10.1101/Im.408507)

Krause, E. T., Naguib, M., 2014. Effects of parental and own early developmental conditions on the phenotype in zebra finches (Taeniopygia guttata). Evol. Ecol. 28, 263-275.

Krech, D., Rosenzweig, M.R., Bennett, E.L., 1960. Effects of environmental complexity and training on brain chemistry. J. Comp. Physiol. Psychol. 53, 509-519.

Lazic, M., Schneider, S.M., Lickliter, R., 2007. Enriched rearing facilitates spatial exploration in northern bobwhite (Colinus virginianus) neonates. Dev. Psychobiol. (doi:10.1002/dev.20230)

Levine, S., Alpert, M., Lewis, G.W., 1957. Infantile experience and the maturation of the pituitary adrenal axis. Science 126:1347.

Light, K.R., Kolata, S., Hale, G., Grossman, H., Matzel, L.D., 2008. Up-regulation of exploratory tendencies does not enhance general learning abilities in juvenile or young-adult outbred mice. Neurobiol. Learn. Mem. 90, 317-329. 
Light, K.R., Grossman, H., Kolata, S., Wass, C., Matzel, D., 2011. General learning ability regulates exploration through its influence on rate of habituation. Behav. Brain. Res. 223, 297-309. (doi:10.1016/j.bbr.2011.04.050)

Lima, S.L., Dill, L.M., 1990. Behavioral decisions made under the risk of predation a review and prospectus. Can. J. Zool. 68, 619-640.

Lukkes, J.L., Mokin, M.V., Scholl, J.L., Forster, G.L., 2009. Adult rats exposed to early-life social isolation exhibit increased anxiety and conditioned fear behavior, and altered hormonal stress responses. Horm. Behav. 55, 248-256

Mathot, K. J., Wright, J., Kempenaers, B., Dingemanse, N. J., 2012. Adaptive strategies for managing uncertainty may explain personality-related differences in behavioural plasticity. Oikos 121 , 1009-1020.

Meaney, M.J., Mitchell, J.B., Aitken, D.H., Bhatnagar, S., Bodnoff, S.R., Iny, L.J., Sarrieau, A., 1991. The effects of neonatal handling on the development of the adrenocortical response to stress: implications for neuropathology and cognitive deficits in later life. Psychoneuroendocrinology $16,85-103$

Matzel, L.D., Han, Y.R., Grossman, H., Karnik, M.S., Patel, D., Scott, N., 2003. Individual differences in the expression of a 'general' learning ability in mice. J. Neurosci. 16, 6423-6433.

Moser, E. I., Moser, M. B., Andersen, P., 1994. Potentiation of dentate synapses initiated by exploratory learning in rats: dissociation from brain temperature, motor activity, and arousal. Learn. Mem. $1,55-73$.

Naguib, M., Flörcke, C., van Oers, K., 2011. Effects of social conditions during early development on stress response and personality traits in great tits (Parus major). Dev. Psychobiol. 53, 592-600.

Neto, J.B.B., Tiba, P. A., Faturi, C. B., de Castro-Neto, E. F., da Graça Naffah-Mazacoratti, M., de Jesus Mari, J., Suchecki, D., 2012. Stress during development alters anxiety-like behavior and hippocampal neurotransmission in male and female rats. Neuropharmacology 62, 518-526.

Noguera, J.C., Metcalfe, N.B., Surai, P.F., Monaghan, P., 2015. Are you what you eat? Micronutritional deficiencies during development influence adult personality-related traits. Anim. Behav. 101, 129-140.

Osorio, D., Vorobyev, M., Jones, C.D., 1999. Colour vision of domestic chicks. J. Exp. Biol. 202, 29512959.

Oken, B. S., Salinsky, M. C., \& Elsas, S. M., 2006. Vigilance, alertness, or sustained attention: physiological basis and measurement. Clinical Neurophys. 117, 1885-1901.

Papaioannou, A., Gerozissis, K., Prokopiou, A., Bolaris, S., Stylianopoulou, F., 2002. Sex differences in the effects of neonatal handling on the animal's response to stress and the vulnerability for depressive behaviour. Behav. Brain. Res. 129, 131-139. 
Patzke, N., Ocklenburg, S., van der Staay., F.J., Güntürkün, O., Manns, O., 2009. Consequences of different housing conditions on brain morphology in laying hens. J Chem. Neuroanat. 37, 141148.

Reale, D., Reader, S.M., Sol, D., McDougall, P.T., Dingemanse, N.J., 2007. Integrating animal temperament within ecology and evolution. Biol. Rev. Camb. Philos. Soc. 82, 291-318.

Rosenzweig, M.R., Krech, D., Bennett, E.L., Diamond, M.C. 1962. Effects of environmental complexity and training on brain chemistry and anatomy: a replication and extension. J. Comp. Physiol. Psychol. 55, 429.

Schuett, W., Dall, S.R.X., Wilson, A. J., Royle, N.J., 2013. Environmental transmission of a personality traits: foster parent exploration behaviour predicts offspring exploration behaviour in zebra finches. Biol. Lett. 9, 20130120. (doi: 10.1098/rsbl.2013.0120)

Shettleworth, S.J., 2010. Cognition, evolution, and behaviour, second ed. Oxford: Oxford University Press.

Schielzeth, H., 2010. Simple means to improve the interpretability of regression coefficients. Methods Ecol. Evol. 1, 103-113.

Sih, A., Bell, A.M., Johnson, J.C., Ziemba, R.E., 2004. Behavioral syndromes: An integrative overview. Q. Rev. Biol. 79, 241-558. (URL: http://www.jstor.org/stable/10.1086/422893)

Sih, A., Del Giudice, M., 2012. Linking behavioural syndromes and cognition: a behavioural ecology perspective. Phil. Trans. R. Soc. B. 367, 2762-2772. (doi:10.1098/rstb.2012.0216)

Skaug, H., Fournier, D., Nielsen, A., Magnusson, A., Bolker, B., 2011. glmmADMB: generalized linear mixed models using AD model builder. R Package, version 0.7.

Smith, B.R., Blumstein, D.T., 2008. Fitness consequences of personality: a meta-analysis. Behav. Ecol. 19, 448-455. (doi:10.1093/beheco/arm144)

Stamps, J.A., Groothuis, T.G., 2010a. The development of animal personality: relevance, concepts and perspectives. Biol. Rev. Camb. Philos. Soc. 85, 301-325.

Therneau, T., 2012. Coxme: Mixed effects Cox models. R package version 2.3.

Thomas, M., Sing, H., Belenky, G., Holcomb, H., Mayberg, H., Dannals, R., Wagner, H.Jr., Thorpe, D., Popp, K., Rowland, L., Welsh, A., Balwinski, S., Redmond, D., 2000. Neural basis of alertness and cognitive performance impairments during sleepiness. I. Effects of $24 \mathrm{~h}$ of sleep deprivation on waking human regional brain activity. J Sleep Res., 9, 335-352.

Titulaer, M., van Kees, O., Naguib, M., 2012. Personality affects learning performance in difficult tasks in a sex-dependent way. Anim. Behav. 83, 723-730. (doi:10.1016/j.anbehav.2011.12.020)

van Oers, K., de Jong, G., van Noordwijk, A.J., Kempenaers, B., Drent, P.J., 2005. Contribution of genetics to the study of animal personalities: a review of case studies. Behaviour 142, 11851206. (doi: $10.1163 / 156853905774539364)$ 
van Oers, K., Sinn, D.L., 2011. Towards a basis for the phenotypic gambit: advances in the evolutionary genetics of animal personality in: Inoue-Murayama, M., Kawamura, S., Weiss, A. (Eds), From genes to behavior: social structures, personalities, communication by color. NY: Springer, New York, pp. 165-184.

van Oers, K., Kohn, G.M., Hinde, C.A., Naguib, M., 2015. Parental food provisioning is related to nestling stress response in wild great tit nestlings: implications for the development of personality. Front. Zool. 12, S10.

van Praag, H., Kempermann, G., Gage, F.H., 2000. Neural consequences of environmental enrichment. Nature Rev. Neurosci. 1, 191-196.

Wolf, M., van Doorn, G.S., Weissing, F.J., 2008. Evolutionary emergence of responsive and unresponsive personalities. Proc. Natl. Acad. Sci. 105, 15825-15830.

Zidar, J., Løvlie, H., 2012. Scent of the enemy: behavioural responses to predator faecal odour in the fowl. Anim. Behav. 84, 547-554.

Zuk, M., Thornhill, R., Ligon, J.D., Johnston, K., Austad, S., Ligon, S.H., Thornhill, N.W., Costin, C., 1990. The role of male ornaments and courtship behaviour in female mate choice of red jungle fowl. Am. Nat. 136, 459-473. (URL: http://www.jstor.org/stable/2462188)

Zuur, A.F., leno, E.N., Walker, N.J., Saveliev, A.A., Smith, G.M., 2009. Mixed effects models and extensions in ecology with R. Springer Science and Business Media, New York. 


\section{Figures and tables}

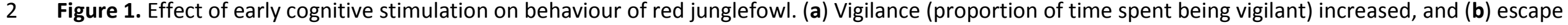

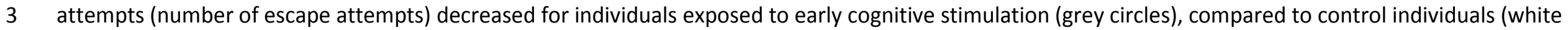
4 circles) when assayed as adults in novel arena -, and novel object tests. Whiskered bars indicate marginal means \pm SE predicted by the best model. Circles 5 show observed values, with circle size proportional to number of observations.
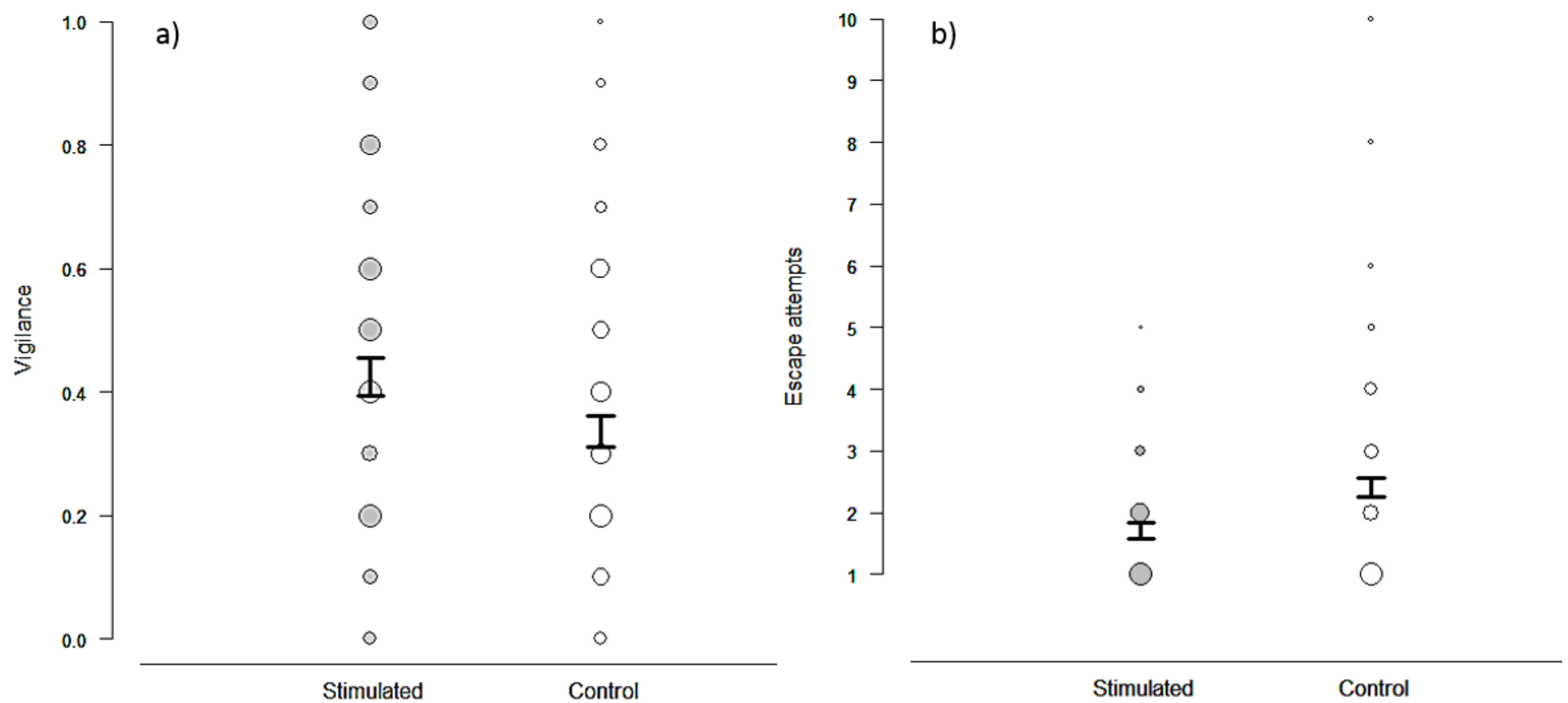
7 Table 1. Between- and within- behaviour correlations for red junglefowl assayed in novel arena and 8 novel object personality tests.

\begin{tabular}{lccccc}
\hline & Latency to move & Activity & Vigilance & Escape & Foraging \\
\hline Latency to move & $0.26^{* *}$ & $-0.48^{* *}$ & 0.05 & $-0.34^{* *}$ & 0.04 \\
Activity & $-0.35^{* *}$ & $0.28^{* *}$ & $0.39^{* *}$ & $0.43^{* *}$ & $-0.33^{* *}$ \\
Vigilance & -0.08 & $0.56^{* *}$ & $0.43^{* *}$ & $0.53^{* *}$ & $-0.77^{* *}$ \\
Escape & $-0.12^{*}$ & $0.44^{* *}$ & $0.47^{* *}$ & $0.18^{*}$ & $-0.49^{* *}$ \\
Foraging & 0.02 & $-0.38^{* *}$ & $-0.72^{* *}$ & $-0.48^{* *}$ & $0.41^{* *}$
\end{tabular}

9 Values represent Spearman rank correlations, with significance calculated via bootstrapping (number 10 of iterations $=1000$; $^{\prime * \prime} \mathrm{P}<0.05,^{\prime * * \prime} \mathrm{P}<0.01 ; \mathrm{n}_{\text {individuals }}=173$ ). Values above and below the diagonal 11 (grey) represent correlations between behaviours in the novel arena and novel object tests 12 respectively; values on the diagonal show correlations within behaviours across the two tests (rank order consistency, i.e. personality). 
Table 2. Model output for the analyses of red junglefowl behaviour recorded in personality assays. Presented are the effects of early stimulation (treatment vs. control), test type (novel arena test vs. novel object test), sex (male vs. female), and year (2013 vs. 2015 = 'year 2') on: (a) latency to move (in seconds), (b) activity (proportion of time being active), (c) exploration (number of squares visited, 03), (d) vigilance (proportion of time being vigilant), (e) escape attempts (number, 1 - 10; individuals attempting to escape only), (f) foraging (proportion of time foraging), (g) TI inductions (number of trials needed to induce tonic immobility, $1-4)$.

\begin{tabular}{|c|c|c|c|c|}
\hline Behaviour & Predictor & Estimate & SE & 21p \\
\hline \multirow[t]{3}{*}{ a) Latency to move } & novel object test & 0.38 & 0.11 & $<0281$ \\
\hline & sex female & -0.29 & 0.13 & 0,03 \\
\hline & year 2 & 0.63 & 0.13 & $<0.01$ \\
\hline \multirow[t]{3}{*}{ b) Activity } & intercept & -2.11 & 0.07 & $<0^{2} d_{1}$ \\
\hline & novel object test & 0.38 & 0.10 & $<0291$ \\
\hline & sex female & -0.45 & 0.12 & $<0.01$ \\
\hline \multirow[t]{4}{*}{ c) Exploration } & intercept & 0.51 & 0.10 & $\begin{array}{l}26 \\
<0.01\end{array}$ \\
\hline & novel object test & -0.28 & 0.16 & 02078 \\
\hline & sex female & -0.75 & 0.19 & $<0,81$ \\
\hline & year 2 & 1.02 & 0.19 & $<0.01$ \\
\hline \multirow{4}{*}{ d) Vigilance } & intercept & -0.63 & 0.08 & $<0.81$ \\
\hline & stimulation & 0.24 & 0.10 & 0301 \\
\hline & sex female & -0.47 & 0.10 & $<0,01$ \\
\hline & year 2 & -0.47 & 0.12 & $<0.01$ \\
\hline \multirow[t]{4}{*}{ e) Foraging } & intercept & -0.62 & 0.06 & $<0381$ \\
\hline & stimulation & -0.25 & 0.15 & $0_{398}$ \\
\hline & novel object test & -0.40 & 0.10 & $<0.01$ \\
\hline & sex female & 0.35 & 0.15 & $0^{3} .02$ \\
\hline \multirow[t]{2}{*}{ f) Escape attempts } & intercept & -0.28 & 0.17 & $03 \$ 1$ \\
\hline & stimulation & -0.59 & 0.25 & 0,02 \\
\hline \multirow[t]{2}{*}{ g) TI inductions } & intercept & 0.16 & 0.11 & 0.14 \\
\hline & sex female & 0.29 & 0.17 & 0 \\
\hline
\end{tabular}

Terms shown for each behaviour are those represented in the final model(s). Estimates, standard errors (SE) and significance values $(P)$ refer to the single best model $(\triangle A I C<4)$, except for (c) exploration, and (e) foraging, where statistics are obtained through model averaging on final candidate models with comparable support (all within $\triangle \mathrm{AIC}<4$ from the best model). Estimates are presented as the relative difference between the two levels of the predictor (e.g. for sex, a negative value for 'sex female' arises if males have a stronger effect, thus a higher value, than females). 